\title{
Low Somatic Sodium Conductance Enhances Action Potential Precision in Time-Coding Auditory Neurons
}

\author{
Yang Yang, ${ }^{1}$ Bina Ramamurthy, ${ }^{2}{ }^{-}$Andreas Neef, ${ }^{3}$ and Matthew A. Xu-Friedman ${ }^{1}$ \\ ${ }^{1}$ Department of Biological Sciences and ${ }^{2}$ Department of Computer Science and Engineering, University at Buffalo, State University of New York, Buffalo, \\ New York 14260, and ${ }^{3}$ Max Planck Institute for Dynamics and Self-Organization, 37077 Göttingen, Germany
}

Auditory nerve fibers encode sounds in the precise timing of action potentials (APs), which is used for such computations as sound localization. Timing information is relayed through several cell types in the auditory brainstem that share an unusual property: their APs are not overshooting, suggesting that the cells have very low somatic sodium conductance $\left(g_{\mathrm{Na}}\right)$. However, it is not clear how $g_{\mathrm{Na}}$ influences temporal precision. We addressed this by comparing bushy cells (BCs) in the mouse cochlear nucleus with T-stellate cells (SCs), which do have normal overshooting APs. BCs play a central role in both relaying and refining precise timing information from the auditory nerve, whereas SCs discard precise timing information and encode the envelope of sound amplitude. Nucleated-patch recording at nearphysiological temperature indicated that the Na current density was $62 \%$ lower in BCs, and the voltage dependence of $g_{\mathrm{Na}}$ inactivation was $13 \mathrm{mV}$ hyperpolarized compared with SCs. We endowed BCs with SC-like $g_{\mathrm{Na}}$ using two-electrode dynamic clamp and found that synaptic activity at physiologically relevant rates elicited APs with significantly lower probability, through increased activation of delayed rectifier channels. In addition, for two near-simultaneous synaptic inputs, the window of coincidence detection widened significantly with increasing $g_{\mathrm{Na}}$, indicating that refinement of temporal information by BCs is degraded by $g_{\mathrm{Na}}$. Thus, reduced somatic $g_{\mathrm{Na}}$ appears to be an adaption for enhancing fidelity and precision in time-coding neurons.

Key words: cochlear nucleus; dynamic clamp; sodium channels; spike initiation; synaptic transmission; time coding

Significance Statement

Proper hearing depends on analyzing temporal aspects of sounds with high precision. Auditory neurons that specialize in precise temporal information have a suite of unusual intrinsic properties, including nonovershooting action potentials and few sodium channels in the soma. However, it was not clear how low sodium channel availability in the soma influenced the temporal precision of action potentials initiated in the axon initial segment. We studied this using dynamic clamp to mimic sodium channels in the soma, which yielded normal, overshooting action potentials. Increasing somatic sodium conductance had major negative consequences: synaptic activity evoked action potentials with lower fidelity, and the precision of coincidence detection was degraded. Thus, low somatic sodium channel availability appears to enhance fidelity and temporal precision.

\section{Introduction}

The timing of action potentials (APs) is used in the auditory system to encode sound features. Extremely precise timing of APs, on the scale of $10 \mu \mathrm{s}$, carries information for behaviorally important functions, such as sound localization (Grothe, 2003).

\footnotetext{
Received May 4, 2016; revised Sept. 21, 2016; accepted Oct. 4, 2016.

Author contributions: Y.Y., B.R., A.N., and M.A.X.-F. designed research; Y.Y. and A.N. performed research; Y.Y., A.N., and M.A.X.-F. analyzed data; Y.Y., B.R., A.N., and M.A.X.-F. wrote the paper.

This work was supported by National Science Foundation Grant 1208131, German Ministry for Education and Research Grant 01GQ1204, and the Paul Pizzella and Marta Ayala Travel Award. We thank T. Moser and T. Butola for providing invaluable support while collecting nucleated-patch data; and T. Ngodup, G. Si, N. Wong, H. Yang, and X. Zhuang for helpful comments on the experiments and manuscript.

The authors declare no competing financial interests.

Correspondence should be addressed to Dr. Matthew A. Xu-Friedman, Department Biological Sciences, University at Buffalo, State University of New York, Buffalo, NY 14260. E-mail: mx@buffalo.edu.

DOI:10.1523/JNEUROSCI.1475-16.2016

Copyright $\odot 2016$ the authors $\quad 0270-6474 / 16 / 3611999-11 \$ 15.00 / 0$
}

Relaying accurate timing through early stages of the auditory pathway depends critically on the precision of AP initiation. In most neurons, AP initiation results from synaptically driven activation of $\mathrm{Na}$ channels first at the axon initial segment (AIS) followed immediately by the soma (Edwards and Ottoson, 1958; Bean, 2007), leading to the familiar overshooting AP.

However, there are exceptions to this general rule. Interestingly, several auditory neurons concerned with precise timing have very low-amplitude APs, including bushy cells (BCs) in the anteroventral cochlear nucleus (AVCN) (Oertel, 1983), octopus cells in the posteroventral cochlear nucleus (Golding et al., 1995), and principal cells of the medial superior olive (MSO) (Scott et al., 2005). Mature principal cells of the medial nucleus of the trapezoid body (MNTB) show APs that reach slightly higher peaks, close to $0 \mathrm{mV}$ (Roberts et al., 2014). These neuron types demonstrate additional common characteristics, including low 
input resistance and high rectification to current injection, which are thought to contribute to their remarkable temporal precision for AP initiation, on the order of $20 \mu$ s (Golding et al., 1995; Xu-Friedman and Regehr, 2005a; Gittelman and Tempel, 2006). Small APs are also found in time-coding neurons in the avian auditory pathway in nucleus magnocellularis and nucleus laminaris (Kuba et al., 2006; Kuba and Ohmori, 2009). The reason for this unusual intrinsic property is unclear.

One possibility has been investigated in MSO neurons. An interesting study found that the somatic Na channels of MSO neurons had a negatively shifted inactivation voltage sensitivity (Scott et al., 2010). Despite this, the Na channels appeared to be activated by synaptic potentials, significantly amplifying them. However, this does not explain why somatic $\mathrm{Na}$ channels have such unusual inactivation sensitivity. Computer models indicate that MSO APs initiate normally in the AIS or even at more distant nodes of Ranvier (Lehnert et al., 2014), and models of their analogous neurons in nucleus laminaris suggest that initiating APs far down the axon and excluding $\mathrm{Na}$ channels from the soma enhance sensitivity to interaural time differences (Kuba et al., 2006; Ashida et al., 2007). Thus, somatic Na channels could modulate responsiveness of the AIS Na channels that initiate the AP.

To test directly whether somatic $g_{\mathrm{Na}}$ interferes with AP reliability and precision in this class of time-coding neurons, we focused on BCs in the AVCN. We used nucleated patches to measure the biophysical properties of $\mathrm{Na}$ channels in BCs as well as T-stellate cells (SCs) in the AVCN, which have overshooting APs. Our results revealed that $g_{\mathrm{Na}}$ density in BCs was lower, and the voltage for half-maximal inactivation was more hyperpolarized compared with SCs. Both factors reduced availability of somatic $g_{\mathrm{Na}}$ in BCs during AP initiation. Then we used dynamic clamp to add $g_{\mathrm{Na}}$ to BCs, which decreased AP probability and precision in response to synaptic activation by enhancing $\mathrm{K}$ channel activation. The precision of coincidence detection was also significantly degraded with $g_{\mathrm{Na}}$. Thus, low levels of somatic $g_{\mathrm{Na}}$ seem to enhance fidelity and temporal precision in this class of specialized neurons.

\section{Materials and Methods}

Slice preparation. Experimental procedures were approved by the Institutional Animal Care and Use Committee at the University at Buffalo. Slices were prepared from P14-P25 CBA/CaJ mice (RRID:IMSR_JAX: 000654) of either sex as described previously (Ngodup et al., 2015; Yang and Xu-Friedman, 2015). Briefly, slices $(150 \mu \mathrm{m})$ were cut in an ice-cold solution containing the following (in $\mathrm{mm}$ ): $76 \mathrm{NaCl}, 75$ sucrose, 25 $\mathrm{NaHCO}_{3}, 25$ glucose, $2.5 \mathrm{KCl}, 1.25 \mathrm{NaH}_{2} \mathrm{PO}_{4}, 7 \mathrm{MgCl}_{2}$, and $0.5 \mathrm{CaCl}_{2}$. Slices were transferred to normal ACSF until recording as follows (in mm): $125 \mathrm{NaCl}, 26 \mathrm{NaHCO}_{3}, 2.5 \mathrm{KCl}, 1.25 \mathrm{NaH}_{2} \mathrm{PO}_{4}, 20$ glucose, 1.5 $\mathrm{CaCl}_{2}, 1 \mathrm{MgCl}_{2}, 4 \mathrm{Na}$-L-lactate, $2 \mathrm{Na}$-pyruvate, and $0.4 \mathrm{Na}$-L-ascorbate, bubbled with $95 \% \mathrm{O}_{2}-5 \% \mathrm{CO}_{2}$. The recording chamber was perfused at 3-4 $\mathrm{ml} / \mathrm{min}$ using a pump (403U/VM2; Watson-Marlow), with saline running through an in-line heater to maintain the temperature at $34^{\circ} \mathrm{C}$ (SH-27B with TC-324B controller; Warner Instruments).

Cells were patched under an Olympus BX51 microscope with a Multiclamp 700B (Molecular Devices) controlled by the National Instruments PCI-6221, driven by custom-written software running in Igor (WaveMetrics). Recordings were performed in the presence of $10 \mu \mathrm{M}$ strychnine to block glycine receptors.

Nucleated patch recordings. Pipettes were pulled from borosilicate glass (OD: $1.5 \mathrm{~mm}$, ID: $0.86 \mathrm{~mm}$; Sutter Instruments) to a resistance of 3-4 M $\Omega$ and filled with internal solution containing the following (in $\mathrm{mM}$ ): $135 \mathrm{CsCl}$, 5 EGTA, 10 HEPES, 4 ATP-Na 2,20 TEA, $2 \mathrm{NaOH}$, pH 7.3, 305 mOsm. BCs were identified in AVCN slices by spontaneous mEPSCs with half-width $\leq 0.5 \mathrm{~ms}$ (width at $50 \%$ of the peak amplitude). SCs had mEPSCs with half-width $>0.5 \mathrm{~ms}$ (Chanda and Xu-Friedman, 2010b). Once cell identity was established, nucleated patches (Schmidt-Hieber and Bischofberger, 2010) were generated by applying constant negative pressure to the pipette, which was then pulled out of the brain slice. $\mathrm{Na}$ currents were isolated by adding to the ACSF as follows (in mM): $10 \mathrm{TEA}, 2 \mathrm{CoCl}_{2}, 0.5 \mathrm{NiCl}_{2}$, and 0.05 $\mathrm{CdCl}_{2}$. Data were low-pass filtered at $10 \mathrm{kHz}$ (four-pole Bessel) and acquired at $100 \mathrm{kHz}$. The junction potential was measured as $9 \mathrm{mV}$, which is close to the theoretical value of $10 \mathrm{mV}$ according to Clampex. Data were not corrected for liquid junction potential.

Current- and dynamic-clamp recordings. The internal solution in current- and dynamic-clamp patch pipettes contained the following (in $\mathrm{mm}$ ): $130 \mathrm{KMeSO}_{3}, 10 \mathrm{NaCl}, 2 \mathrm{MgCl}_{2}, 0.16 \mathrm{CaCl}_{2}, 0.5 \mathrm{EGTA}, 10$ HEPES, $4 \mathrm{Na}_{2} \mathrm{ATP}, 0.4 \mathrm{NaGTP}$, and 14 Tris-CrPhos, pH 7.2, $302 \mathrm{mOsm}$. The junction potential for this solution in normal ACSF was calculated as 8.6 $\mathrm{mV}$ in Clampex, and no further correction was done. For current clamp, cells were patched with 1-2 M $\Omega$ pipettes. For dynamic clamp, BCs were patched simultaneously with two $3-5 \mathrm{M} \Omega$ pipettes. One electrode measured cell voltage, and the other passed current. Resting potential was maintained at $-60 \mathrm{mV}$ between trials by passing small currents. For experiments with evoked synaptic responses, auditory nerve fibers (ANFs) were isolated and stimulated using 6-20 $\mu \mathrm{A}$ pulses passed through a small glass micropipette placed in the neuropil. Train stimuli were applied every $30 \mathrm{~s}$.

BCs, SCs, octopus cells, and DCN fusiform cells were recorded in sagittal sections of the cochlear nucleus. BCs can be reliably distinguished from SCs by their response to strong depolarizing current pulses with single, undershooting APs (Wu and Oertel, 1984). Octopus cells are located near the border between AVCN and DCN and show undershooting APs. DCN fusiform cells are recognized by their elongated shape and distinguished from cartwheel cells by the absence of complex APs. MNTB and lateral olivocochlear (LOC) neurons were recorded in transverse sections of the brainstem. LOC neurons are located in the lateral superior olive, and are identified by their large soma and delayed response to depolarizing current pulses (Adam et al., 1999; Sterenborg et al., 2010).

The Markov feature of mafDC was used to apply $g_{\mathrm{Na}}$ (Yang et al., 2015). The Na channel model was based on the Na currents recorded in Figure 2. We assessed the speed of the dynamic clamp using the test feature of mafDC, which depended on the specific experimental conditions. When the dynamic clamp was used for $g_{\mathrm{Na}}$ alone (see Fig. 5), the speed was $20 \mu \mathrm{s} /$ cycle $(50 \mathrm{kHz}$ ), the latency was $30 \mu \mathrm{s}$, and the jitter was $6 \mu$ s. For both $g_{\mathrm{Na}}$ and current pulse (see Fig. 4), the speed was $29 \mu \mathrm{s} / \mathrm{cycle}$ ( $35 \mathrm{kHz}$ ), the latency was $48 \mu \mathrm{s}$, and the jitter was $9 \mu \mathrm{s}$. For $g_{\mathrm{Na}}$ and $g_{\mathrm{AMPA}}$ (see Figs. 6; 7), the speed was $28 \mu \mathrm{s} / \mathrm{cycle}(36 \mathrm{kHz}$ ), the latency was $47 \mu \mathrm{s}$, and the jitter was $9 \mu \mathrm{s}$.

Data are presented as mean \pm SEM. Significance was determined using paired or unpaired, two-tailed, Student's $t$ test, except where otherwise stated.

\section{Results}

\section{Auditory neurons that process precise timing lack} somatic APs

We first examined representative neurons in the auditory pathway that do not encode precise timing: SCs in the AVCN, LOC neurons in the lateral superior olive, and fusiform cells in the DCN. SCs encode sound amplitude and in vivo fire a burst of APs not locked to the stimulus (Frisina et al., 1985; Kim et al., 1990). LOC neurons form an efferent pathway regulating cochlear responses (Vetter and Mugnaini, 1992). DCN fusiform cells integrate auditory and nonauditory inputs to control movement and balance (Oertel and Wu, 1989; Shore, 2005). All these cells fired normal overshooting APs (Fig. $1 A-C$, top). We also examined the properties of APs using phase-plane plots, which show the derivative of membrane potential $\left(d V_{\mathrm{m}} / d t\right)$ as a function of instantaneous membrane potential. Phase-plane plots of APs in these cells showed two distinct phases (Fig. $1 A-C$, bottom traces), and this was consistent in each cell examined (Fig. $1 G$, solid bars). The first, low-threshold phase is thought to reflect Na channel activa- 

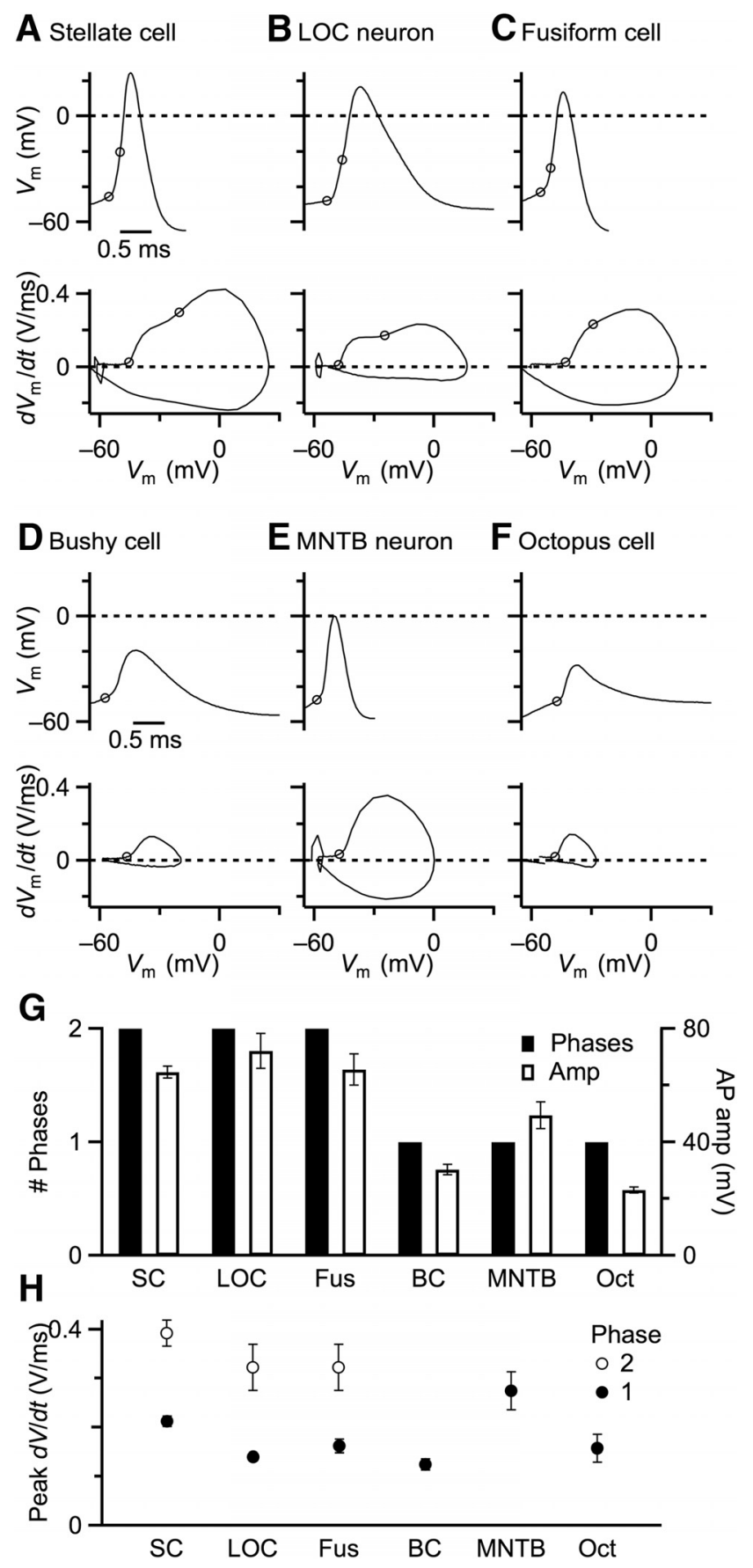

Figure 1. APs of auditory neurons. $\boldsymbol{A}-\boldsymbol{F}$, Representative single traces from neurons with overshooting $\mathrm{APs}(\boldsymbol{A}-\boldsymbol{C})$ and nonovershooting $\mathrm{APs}(\boldsymbol{D}-\boldsymbol{F})$. Top traces represent responses to current injection $(600 \mathrm{pA})$. Bottom traces represent phase-plane plots. The start of each phase is indicated by open circles on the phase-plane plots with the corresponding time on the top traces. $\mathbf{G}, \boldsymbol{H}$, Quantification of auditory APs, showing number of phases in phase-plane plots ( $\boldsymbol{G}$, solid bars), overall AP amplitude ( $\boldsymbol{G}$, open bars), amplitude of first ( $\boldsymbol{H}$, closed circles), and second phases ( $\boldsymbol{H}$, open circles). Values are mean \pm SEM.

tion in the AIS, followed by a second, larger amplitude phase, which is the somatic AP (Bean, 2007).

We compared these against auditory neurons that have a number of cellular specializations associated with precise AP timing: BCs in the AVCN, principal neurons in MNTB, and octopus cells in posteroventral cochlear nucleus. BCs relay temporal information from ANFs to MNTB neurons (Spirou et al., 1990; Kuwabara et al., 1991; Smith et al., 1991; von Gersdorff and Borst,
2002), which in turn relay precise timing information to various auditory brainstem targets (Joris et al., 1998; Brand et al., 2002). Octopus cells integrate temporal information across groups of ANFs (Golding et al., 1995; Oertel et al., 2000). All these cells had nonovershooting APs (Fig. $1 D-F$, top traces). The phase-plane plots of these cells showed a single phase, most likely from the AIS (Fig. 1D-F, bottom traces), and this was consistent in multiple cells of each type (Fig. $1 G$, solid bars).

We quantified AP characteristics from several cells of each type (5 SCs, 4 LOC neurons, 6 DCN fusiform cells, 5 BCs, 6 MNTB neurons, 3 octopus cells). The three cell types with 2 phases had high-amplitude APs, whereas the three cell types with 1 phase had low-amplitude APs (Fig. $1 G$, open bars). We also quantified the peak derivative for each AP phase in both groups. In cells with two phases, if a clear maximum was not reached for the first phase, then the amplitude was taken from the inflection point between the two phases. The first phases had very similar amplitudes across all cell types, except for MNTB neurons, which were larger (Fig. $1 \mathrm{H}$, closed symbols). This suggests that the AIS functions similarly across all the neurons we considered. For the cells with second phases, the peak rate of depolarization was similar (Fig. $1 H$, open symbols), suggesting that $\mathrm{Na}$ channel activation in the soma was similar for that group of neurons. These data indicate that there is a significant dichotomy in AP characteristics, with a specialized subset that possesses cellular characteristics associated with precise timing appearing to lack somatic APs.

\section{Properties of somatic Na currents in BCs and SCs}

We investigated why BCs lack a somatic AP by comparing with neighboring SCs, which do have somatic APs. We compared the properties of somatic $\mathrm{Na}$ currents using nucleated patches. This approach allowed excellent voltage control, isolation of strictly somatic Na channels, and reduced patch capacitance, all of which were important for rapid recordings near physiological temperature.

We measured the voltage dependence of $g_{\mathrm{Na}}$ activation by holding patches at $-120 \mathrm{mV}$ and stepping to $V_{\text {step }}$ from -110 to $20 \mathrm{mV}$. Na currents during the depolarizing capacitance transient were revealed by adding the inverse capacitance transient occurring at the end of the voltage pulse. Na currents were pharmacologically isolated by using TEA, $\mathrm{Co}^{2+}, \mathrm{Ni}^{2+}$, and $\mathrm{Cd}^{2+}$ to block $\mathrm{K}$ and $\mathrm{Ca}$ channels. Representative individual traces are shown for a SC and $\mathrm{BC}$ in Figure $2 A$, showing current that activated and inactivated extremely rapidly. In the currents of Figure $2 A$, the fastest activation reached a peak within $\sim 100 \mu \mathrm{s}$, and inactivation had a decay $\tau$ of $<0.2 \mathrm{~ms}$. We confirmed that these were $\mathrm{Na}$ currents by applying TTX $(1 \mu \mathrm{M})$, which completely abolished the remaining current (Fig. 2Aiii,iv). This gives us high confidence in the quality of the voltage clamp in dealing with such fast currents. We derived $I-V$ curves for the data in Figure $2 A$, which showed that the amplitude of $\mathrm{Na}$ current was maximal at $\sim-10$ $\mathrm{mV}$ in both BCs and SCs (Fig. 2B). We converted these currents to conductances using the relationship $g_{\mathrm{Na}}=I /\left(V_{\text {step }}-E_{\mathrm{Na}}\right)$. We estimated $E_{\mathrm{Na}}$ to be $72 \mathrm{mV}$ based on the Nernst equation for our experimental conditions, and $70 \mathrm{mV}$ by linear extrapolation of the $I-V$ curve, which are in very close agreement, again giving us confidence in the quality of our voltage clamp. After converting to conductance, we normalized to the maximal conductance $g_{\max }$ and plotted against $V_{\text {step }}$ to obtain activation curves (Fig. 2C). BCs and SCs showed similar voltage dependence of activation.

To compare inactivation characteristics, the nucleated patches were held at voltages $\left(V_{\text {hold }}\right)$ from -150 to $-20 \mathrm{mV}$ and stepped to $0 \mathrm{mV}$ (Fig. $2 D$ ). Normalized conductance $g / g_{\max }$ was 

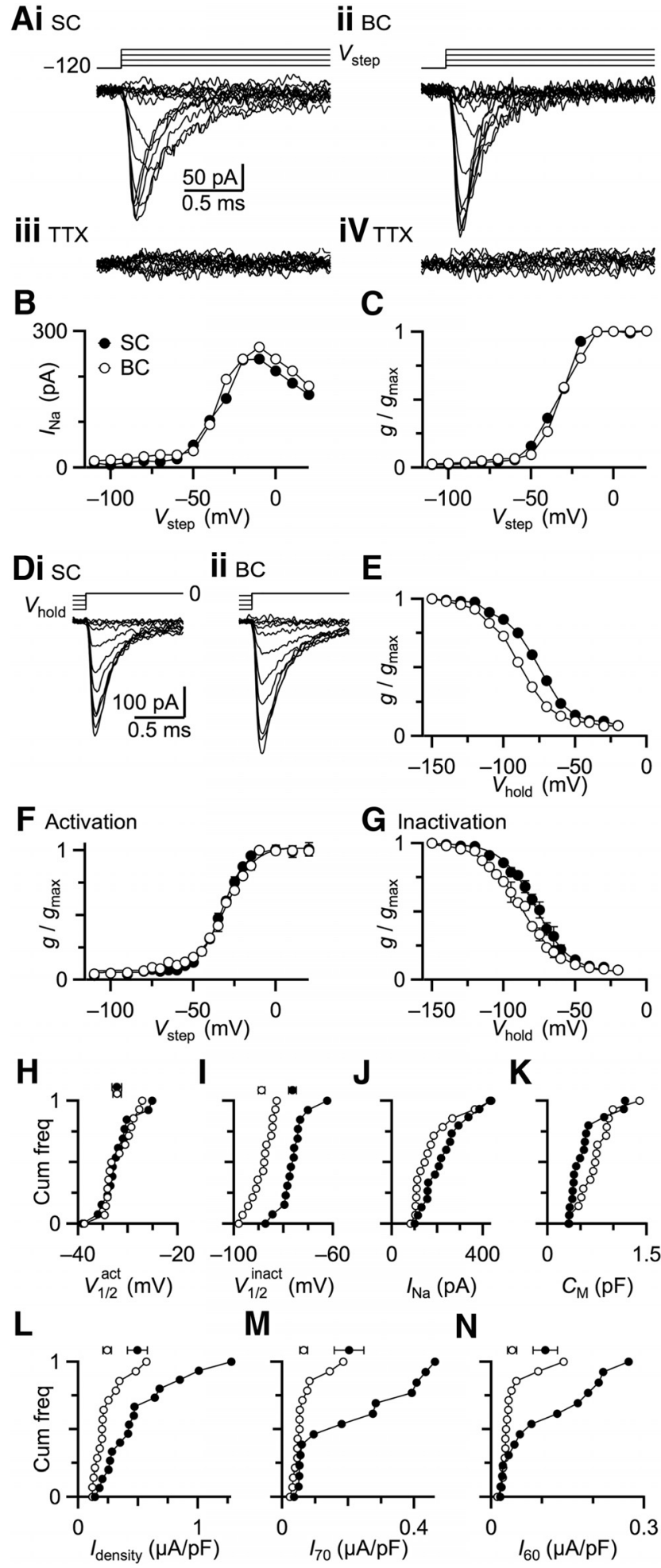

$\mathrm{M}$

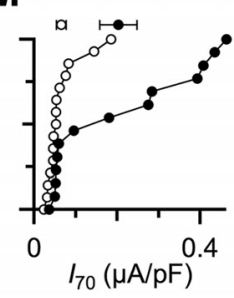

$\mathbf{N}$

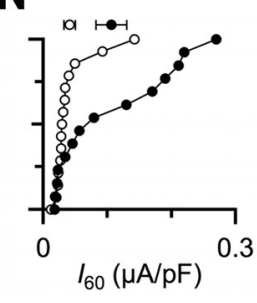

Figure 2. Na currents in $B C s$ show negative shift of inactivation sensitivity and low current density. $\boldsymbol{A}$, Measuring Na channel activation in nucleated patches from a representative SC (i) and $B C$ (ii). Top traces represent the voltage command, which was stepped from $-120 \mathrm{mV}$ to $V_{\text {step }}$ between -110 and $-20 \mathrm{mV}$. Bottom traces represent recorded Na currents. iii, iv, TTX abolished remaining current, confirming it is Na current. $\boldsymbol{B}$, Peak Na current for the $S C$ in $\boldsymbol{A i}$ and $B C$ in Aii for different $V_{\text {step. }}$ C, Normalized conductances calculated from curves in B. D, Measuring $\mathrm{Na}$ channel inactivation from a representative $\mathrm{SC}(\boldsymbol{i})$ and $\mathrm{BC}$ (ii). Top traces represent the voltage command, which was held at $V_{\text {hold }}$ from -150 to $-20 \mathrm{mV}$ and stepped to $0 \mathrm{mV}$. $\boldsymbol{E}$, Normalized conductance as a function of $V_{\text {hold }}$ for the cells in $\boldsymbol{D}$. $\boldsymbol{F}$, Average activation curves from $14 \mathrm{SCs}$ (closed circles) and $15 \mathrm{BCs}$ (open circles). Data were fit with a Boltzmann function: $g / g_{\max }=1 /\left\{1+\exp \left[\left(V_{1 / 2}^{\text {act }}-V\right) / k_{\text {act }}\right]\right\}$, with $V_{1 / 2}=-33.0 \mathrm{mV}, k=7.1 \mathrm{mV}$ for plotted against $V_{\text {hold }}$ to obtain steady-state inactivation curves (Fig. 2E). The steady-state inactivation curve of the BC was shifted to more hyperpolarized values, similar to what was found in MSO neurons (Scott et al., 2010).

We found similar results in 14 SCs and 15 BCs. Averages of activation and inactivation curves are shown in Figure $2 F, G$. The activation data of individual cells was fitted with a Boltzmann function as follows:

$$
g / g_{\max }=1 /\left\{1+\exp \left[\left(V_{1 / 2}^{\text {act }}-V\right) / k_{\text {act }}\right]\right\}
$$

The two cell types did not differ significantly in slope factor, $k_{\text {act }}$ (SCs: $7.7 \pm 0.7 \mathrm{mV}$; BCs: $8.3 \pm 0.9 \mathrm{mV} ; p=0.11$ ) or in halfactivation voltage, $V_{1 / 2}^{\text {act }}$ (SCs: $-35.1 \pm 1.2 \mathrm{mV}$; BCs: $-34.2 \pm 1.0$ $\mathrm{mV} ; p=0.58$; Fig. $2 H)$. The inactivation data were also fitted with an equivalent Boltzmann function. The slope factor $k_{\text {inact }}$ of the inactivation curve was significantly different between SCs and BCs (SCs: $-12.1 \pm 0.3 \mathrm{mV}$; BCs: $-13.9 \pm 0.2 \mathrm{mV} ; p<0.001$ ), indicating that the voltage dependence of inactivation is significantly steeper for BCs. In addition, the half-inactivation voltage $V_{1 / 2}^{\text {inact }}$ was strongly hyperpolarized in BCs compared with SCs (SCs: $-73.1 \pm 1.9 \mathrm{mV}$; BCs: $-86.2 \pm 1.4 \mathrm{mV}$; $p<0.001$; Fig. $2 I$ ). The hyperpolarization of $V_{1 / 2}^{\text {inact }}$ likely decreases the proportion of available (i.e., deinactivated) $\mathrm{Na}$ channels in $\mathrm{BC}$ somata, contributing to the lack of somatic AP.

We also compared the amplitude of the Na currents. The peak magnitude of the Na current was highly variable across patches (Fig. 2J). One source of this variability was rapid rundown of $\mathrm{Na}$ currents. We tried to minimize this effect by completing recordings as quickly as possible, and keeping the delays similar across $\mathrm{BC}$ and SC recordings. A second source of variability was the size of patches, which can be estimated by quantifying capacitance (Fig. 2K) (Gentet et al., 2000). Peak current was normalized to patch capacitance to yield the current density $\left(I_{\text {density }}\right)$, which was significantly lower in BCs compared with SCs $(U=51.5, p=$ 0.0054, two-tailed Mann-Whitney-Wilcoxon test; Fig. 2L). Functionally, what is important to spiking is the availability of $\mathrm{Na}$ channels, which is affected by both their density and the degree of inactivation around resting membrane potential. Resting membrane potential is near $-60 \mathrm{mV}$ for both BCs and SCs (Oertel, 1983). We compared $I_{\text {density }}$ at $-70 \mathrm{mV}$ (Fig. $2 M$ ) and $-60 \mathrm{mV}$ (Fig. $2 N$ ), and both were lower in BCs compared with SCs. The difference was significant at $-70 \mathrm{mV}(U=47, p=0.0091$, twotailed Mann-Whitney-Wilcoxon test), but not at $-60 \mathrm{mV}(U=$ $67, p=0.093$ ). Thus, the low availability of $\mathrm{Na}$ channels at rest probably causes BCs to lack somatic APs.

\section{Na channel model and dynamic clamp}

We wanted to understand how the precision of AP initiation in BCs would change if they expressed $\mathrm{Na}$ channels like those that SCs have. To address this, we aimed to use dynamic clamp to mimic current based on a model of $g_{\mathrm{Na}}$. We used a simple 6-state Markov model with 2 closed states $\left(\mathrm{C}_{1}, \mathrm{C}_{2}\right), 3$ inactivated states

SCs and $V_{1 / 2}=-31.5 \mathrm{mV}, k=8.1 \mathrm{mV}$ for BCs. G, Average inactivation curves from $14 \mathrm{SCS}$ (closed circles) and $15 \mathrm{BCs}$ (open circles). Data were fitted with a Boltzmann function, with $V_{1 / 2}=-75.4 \mathrm{mV}, k=-12.1 \mathrm{mV}$ for SCs and $V_{1 / 2}=-87.7 \mathrm{mV}, k=-13.9 \mathrm{mV}$ for BCs. $\boldsymbol{H}-\boldsymbol{N}$, Comparisons of $\mathrm{BCS}$ and $\mathrm{SCS}$. Plots are cumulative histograms of data from individual patches, and markers at the top are mean \pm SEM. $\boldsymbol{H}$, Half-activation voltages. I, Halfinactivation voltages. J, Maximal Na current amplitudes. $\boldsymbol{K}$, Membrane capacitance of nucleated patches. $\boldsymbol{L}$, Maximal $N$ a current densities from data in $\boldsymbol{J}$ and $\boldsymbol{K} . \boldsymbol{M}, \boldsymbol{N}$, The Na current densities available at $-70 \mathrm{mV}(\boldsymbol{M})$ and $-60 \mathrm{mV}(\boldsymbol{N})$. 
A

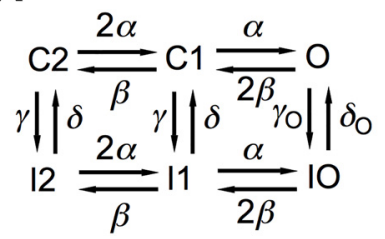

B

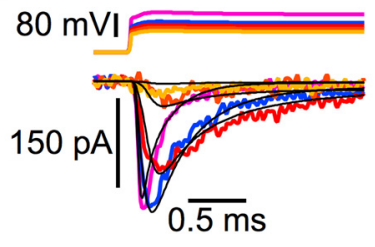

C Activation

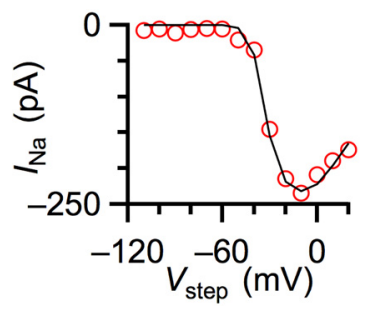

D Inactivation

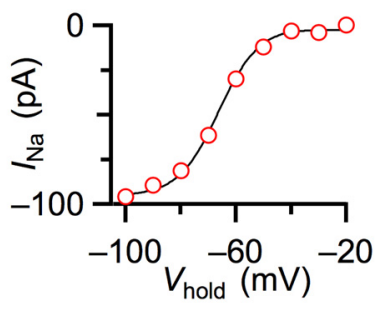

Figure 3. Na channel model. $\boldsymbol{A}$, Gating scheme of the six-state kinetic Markov model used for reproducing Na channel-gating properties. $\boldsymbol{B}$, Top traces represent voltage pulse protocol. Bottom traces represent simulated Na currents using the model (black traces) matched with the actual current traces (color traces). C, D, Predictions of Markov model of Na current (black lines) compared with data recorded (red circles), for peak activation ( $\boldsymbol{C}$ ) and inactivation (D).

Table 1. Transition rates for Markov model of $g_{\mathrm{Na}}$ in Figure $3^{a}$

\begin{tabular}{lcc}
\hline Rate & $A(s)$ & $B(\mathrm{mV})$ \\
\hline$\alpha$ & 97719.6 & 30.8128 \\
$\beta$ & 1088.88 & -8.99497 \\
$\gamma$ & 1714.73 & 15.0341 \\
$\delta$ & 0.164334 & -13.7795 \\
$\gamma_{0}$ & 3320.14 & 110.382 \\
$\delta_{0}$ & 0.104053 & -11.7251 \\
\hline
\end{tabular}

${ }^{a}$ Each transition rate is voltage-dependent according to the equation, $X(V)=A$ exp $(V / B)$, with $A$ and $B$ given according to the table.

$\left(\mathrm{I}_{1}, \mathrm{I}_{2}, \mathrm{I}_{\mathrm{O}}\right)$, and a single open state $(\mathrm{O})$ (Fig. 3A). The transitions between states were given by voltage-dependent rates $\alpha, \beta, \gamma, \delta$, $\gamma_{\mathrm{O}}$, and $\delta_{\mathrm{O}}$, each of which took the same general form with two free parameters (Table 1). The parameters were adjusted to fit the activation and inactivation data of Figure 2. Example activation data and the model fits are shown in Figure $3 B$. The model yielded activation and inactivation curves very similar to actual data (Fig. $3 C, D)$. Thus, this simple model was successful at capturing $\mathrm{Na}$ channel behavior.

The fast kinetics of Na channels require a dynamic clamp that performs very rapidly. To confirm that the dynamic clamp was fast enough in real cells near physiological temperature, we recorded from BCs with two-electrode dynamic clamp and injected current pulses to elicit APs. We also needed to determine how much $g_{\mathrm{Na}}$ was needed to generate an overshooting AP in BCs. This amplitude could differ from SCs because of differences in cellular architecture and input resistance, so this had to be determined empirically by bracketing the likely $g_{\mathrm{Na}}$ between 0.2 and 1 $\mu \mathrm{S}$. With $g_{\mathrm{Na}}$ of up to $1 \mu \mathrm{S}$, the "Na current" passed by the dynamic clamp increased the depolarization following a stimulus (Fig. 4A, top traces), leading to large, overshooting APs with fast kinetics (Fig. 4A, bottom). The peak conductance and current reached very high levels, which necessitated the use of twoelectrode dynamic clamp to avoid large pipette capacitance artifacts. We verified that $g_{\mathrm{Na}}$ had no effect on input resistance around resting membrane potential $\left(R_{\mathrm{in}}\right.$ at $-60 \mathrm{mV}$ for $0 \mu \mathrm{S}=$

$40.8 \pm 4.6 \mathrm{M} \Omega ; R_{\text {in }}$ for $1 \mu \mathrm{S}=44.3 \pm 3.8 \mathrm{M} \Omega ; p=0.4 ; N=10$; Fig. 4C).

The overshooting APs generated using the dynamic clamp looked quite normal in their kinetics. The half-width of APs decreased as $g_{\mathrm{Na}}$ increased, and for $1 \mu \mathrm{S} g_{\mathrm{Na}}$, APs in BCs were nearly as fast as in SCs $(0.47 \pm 0.05 \mathrm{~ms}$ in $31 \mathrm{BCs}$ vs $0.34 \pm 0.01 \mathrm{~ms}$ in 29 SCs; Fig. 4D). Furthermore the shapes of phase-plane plots in BCs with $g_{\mathrm{Na}}$ implemented in dynamic clamp were qualitatively similar to SCs, notably during the upstroke of the AP (compare Fig. $4 E$ and Fig. $1 A$ ). We quantified the time interval between the first and second phases of the BC AP (Fig. 4E, circles) when using the dynamic clamp. These were similar between SCs and BCs with $g_{\mathrm{Na}}$ added (at $1 \mu \mathrm{S}, 0.21 \pm 0.00 \mathrm{~ms}$ in $24 \mathrm{BCs}$ vs $0.18 \pm 0.00$ $\mathrm{ms}$ in 29 SCs; Fig. $4 F$ ). These results indicated our $g_{\mathrm{Na}}$ model in dynamic clamp ran fast enough to qualitatively and quantitatively reproduce overshooting APs in BCs.

\section{Somatic $g_{\mathrm{Na}}$ reduces AP probability and precision}

We tested how $g_{\mathrm{Na}}$ influenced synaptically evoked APs by recording from BCs using two-electrode dynamic clamp, and stimulating a single ANF at physiologically relevant rates $(200 \mathrm{~Hz})$. Different levels of $g_{\mathrm{Na}}$ were applied by the dynamic clamp on interleaved trials. AP probability, latency, and SD of latency (“jitter") were quantified during the second half of the stimulus train (pulses 11-20) when EPSP amplitudes are relatively uniform. Raster plots show a clear decrease in AP probability for $g_{\mathrm{Na}} \geq 0.2$ $\mu \mathrm{S}$ (Fig. $5 A i$ vs Fig. $5 A i i-i v$ ). We found similar results in 6 experiments. The absolute AP probability, latency, and jitter are shown in Figure $5 B-D$, and the changes relative to control $\left(0 \mu \mathrm{S}_{\mathrm{Na}_{\mathrm{Na}}}\right)$ are shown in Figure $5 E-G$. AP probability decreased significantly $(p<0.02$; Fig. $5 E)$, latency increased $(p<0.02$; Fig. $5 F)$, and jitter increased $(p<0.01$; Fig. $5 G)$. Thus, AP reliability and precision were degraded as a result of somatic $g_{\mathrm{Na}}$.

\section{$g_{\mathrm{Na}}$ suppresses APs by recruiting $\mathrm{K}_{\mathrm{V}} 3$ channels}

The reduction in spiking in the experiments of Figure 5 was surprising because the $\mathrm{Na}$ conductance is fundamentally excitatory, so one might expect an increase in spiking, particularly for EPSPs near threshold. In addition, the AP was accelerated with increased $g_{\mathrm{Na}}$, so one might expect BCs to be able to respond more quickly to subsequent synaptic input. However, we observed the opposite, suggesting that when an AP was triggered, the increased depolarization in the soma recruited processes that interfered with initiation of subsequent APs in the AIS. Two possibilities for a higher-amplitude AP to suppress subsequent APs could be either by increased activation of $\mathrm{K}$ channels, or by increased inactivation of $\mathrm{Na}$ channels in the AIS. Both possibilities were explored by measuring how AP threshold changed with different levels of $g_{\mathrm{Na}}$. We applied pairs of synaptic conductances in dynamic clamp. The first, conditioning pulse was always suprathreshold, followed by a second, test pulse at different time intervals. We quantified the minimum conductance amplitude required to fire an AP during the test pulse ("threshold conductance").

We examined how potassium channel activation influenced the threshold conductance, focusing on $\mathrm{K}_{\mathrm{V}} 1$ and $\mathrm{K}_{\mathrm{V}} 3$ channels, which are likely to be activated in BCs by larger APs (Manis and Marx, 1991; Wang et al., 1994; Grigg et al., 2000). $\alpha$-Dendrotoxin (DTX, $50 \mathrm{nM}$ ), which blocks $\mathrm{K}_{\mathrm{V}} 1$ channels, significantly affected firing of BCs in response to current injection (Fig. 6A) but had only a minor effect on AP shape and afterhyperpolarization (Fig. $6 B)$. We wanted to investigate how transient activation of DTXsensitive channels during the AP might influence subsequent 
threshold, independent of their role in setting resting membrane potential (Cao et al., 2007), so we corrected resting membrane potential to $-60 \mathrm{mV}$ throughout the experiment. DTX had little effect on threshold. In the example of Figure $6 \mathrm{Ci}$, the threshold conductance of the test pulse was $13.6 \mathrm{nS}$ in control, and increased to $18.8 \mathrm{nS}$ when $1 \mu \mathrm{S} g_{\mathrm{Na}}$ was applied using dynamic clamp, consistent with the reduced spiking of Figure 5 . This situation was unchanged by the addition of DTX. In DTX, threshold for the test pulse was $13.9 \mathrm{nS}$ with no added $g_{\mathrm{Na}}$, and increased to $19.0 \mathrm{nS}$ with $1 \mu \mathrm{S} g_{\mathrm{Na}}$ (Fig. 6 Cii). Thus, $\mathrm{K}_{\mathrm{V}} 1$ channels appeared not to contribute to the increase in threshold with added $g_{\mathrm{Na}}$.

We obtained quite different results with tetraethyl ammonium (TEA), which primarily blocks $\mathrm{K}_{\mathrm{V}} 3$ channels at $1 \mathrm{~mm}$ concentration. TEA had a large effect on AP shape, greatly lengthening the duration, and eliminating the afterhyperpolarization (Fig. 6D,E). Most importantly, adding $g_{\mathrm{Na}}$ had less effect on conductance threshold in the presence of TEA. In the representative example of Figure $6 F i$, in control conditions the conductance threshold of the test pulse increased from $20.0 \mathrm{nS}$ to $28.0 \mathrm{nS}$ when $1 \mu \mathrm{S} g_{\mathrm{Na}}$ was applied, similar to Figures 5 and $6 \mathrm{Ci}$. However, after adding TEA, the threshold increased less when $1 \mu \mathrm{S} g_{\mathrm{Na}}$ was applied, from 21.0 to $23.0 \mathrm{nS}$.

Similar results were found in multiple experiments. In control conditions (i.e., no antagonist), addition of $g_{\mathrm{Na}}$ increased the conductance threshold, especially at the shortest intervals and with highest $g_{\mathrm{Na}}$ (Fig. 6G, black symbols; filled symbols mark significant differences compared with $0 \mu \mathrm{S} g_{\mathrm{Na}}$ with $p<0.02$; 9 experiments). This increase in threshold had a duration $(>10 \mathrm{~ms})$ that greatly outlasted both the underlying synaptic conductance $(\sim 0.5 \mathrm{~ms})$ and the AP it triggered $(\sim 2 \mathrm{~ms})$, which indicates that the increase in threshold is a long-lasting aftereffect of the AP. These effects were nearly identical in DTX (Fig. 6G, blue symbols; 4 experiments). When we computed the difference between control and DTX conditions within experiments, DTX had no significant effect on threshold for any level of $g_{\mathrm{Na}}$ at any time intervals $(p>0.18$ for all comparisons between DTX and no drug; Fig. $6 H$, blue symbols), suggesting that $\mathrm{K}_{\mathrm{V}} 1$ channels did not contribute to the increased AP threshold. By contrast, in TEA, changes in threshold after the conditioning pulse were particularly reduced at short intervals and with high $g_{\mathrm{Na}}$ (Fig. 6G, red symbols; 5 experiments). The effects of TEA compared with control were significant for $g_{\mathrm{Na}} \geq 0.2 \mu \mathrm{S}$ and at intervals $\leq 10 \mathrm{~ms}$ (Fig. $6 \mathrm{H}$, red, filled symbols mark comparisons between TEA and no drug with $p<0.04$ ). These results are consistent with increased AP amplitudes enhancing the activation of $\mathrm{K}_{\mathrm{V}} 3$ channels and raising AP threshold, which reduces the likelihood of subsequent APs.
An alternative explanation might be that TEA influences the conductance threshold simply by prolonging the conditioning AP, such as by depolarizing the BC closer to threshold. If that were the case, then TEA should reduce threshold for all levels of $g_{\mathrm{Na}}$. However, this was not what we observed. We saw a large decrease in conductance threshold only when $g_{\mathrm{Na}}$ was added, but not in the absence of added $g_{\mathrm{Na}}$ (Fig. 6Fi, ii, left; Fig. $6 H$, red circles). This indicates that the prolonged AP alone did not reduce conductance threshold.

These results also provide insight into whether increased AP amplitudes significantly inactivate Na channels in the AIS. If larger APs did cause significant inactivation of $\mathrm{Na}$ channels in the AIS, then broadening of APs by TEA application should increase conductance threshold yet further. However, we observed the opposite: adding TEA reduced the conductance threshold during the test pulse (Fig. $6 H$ ), which suggests that taller APs in the soma negligibly inactivate $\mathrm{Na}$ channels in the AIS. Thus, in normal BCs, low levels of somatic $g_{\mathrm{Na}}$ appear to prevent overactivation of $\mathrm{K}_{\mathrm{V}} 3$ channels, supporting the ability of BCs to follow high rates of synaptic activation. 


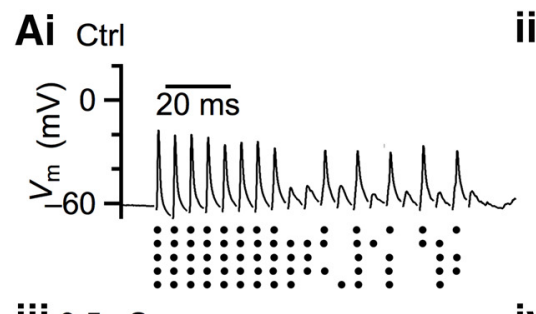

ii $0.2 \mu S g_{\mathrm{Na}}$

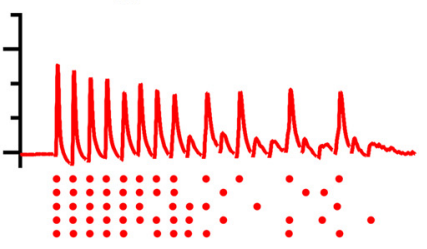

iii $0.5 \mu \mathrm{S}$

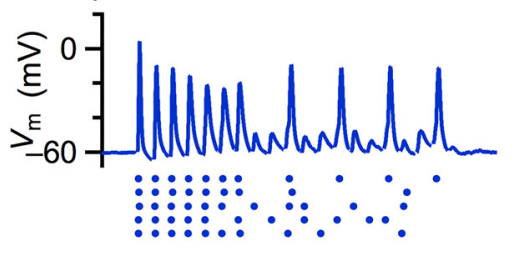

B

C
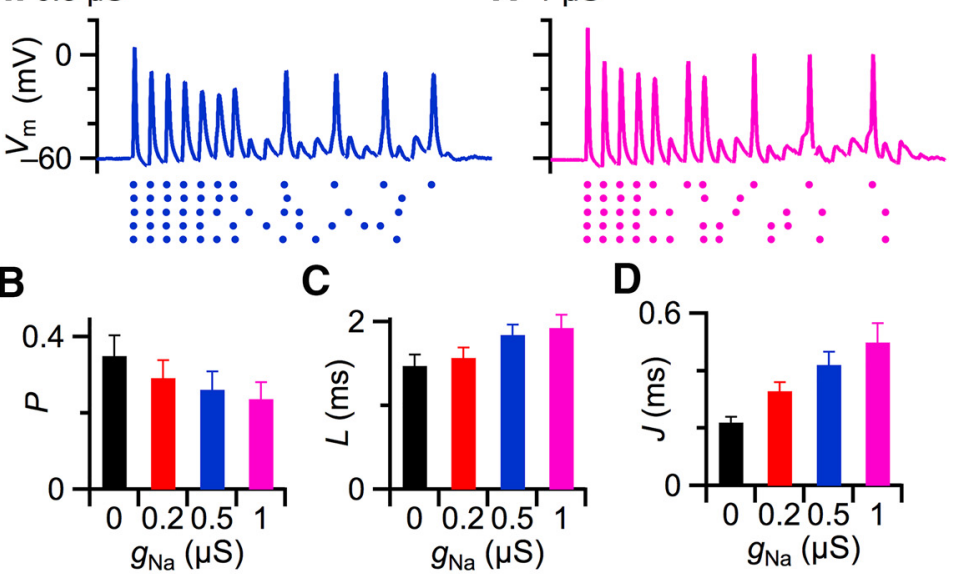

E

$g_{\mathrm{Na}}(\mu \mathrm{S})$

$\mathbf{F}$

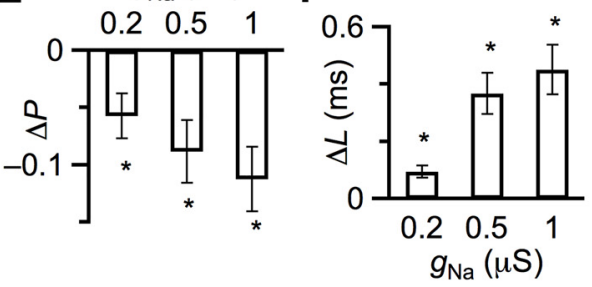

D

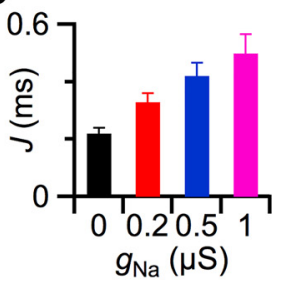

G

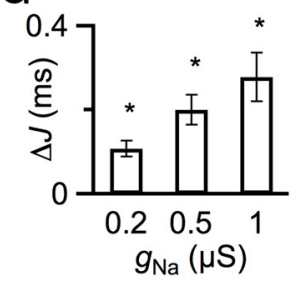

Figure 5. Effects of $g_{\mathrm{Na}}$ on AP probability and timing in response to evoked synaptic activity. $A$, Representative experiment. Top traces represent responses of $B C$ to trains of fiber stimulation at $200 \mathrm{~Hz}$. Stimulus artifacts are removed for clarity. Bottom raster plots represent timing of APs from 5 similar trials. $\boldsymbol{B}-\boldsymbol{D}$. Average measurements from $6 \mathrm{BC}$ s showing effect of $g_{\mathrm{Na}}$ on $(\boldsymbol{B}) \mathrm{AP}$ probability, (C) AP latency, and (D) SD of AP latency (jitter). $\boldsymbol{E}-\boldsymbol{G}$, Changes in AP probability $(\boldsymbol{E})$, latency $(\boldsymbol{F})$, and jitter $(\boldsymbol{G})$ with respect to control $\left(0 \mu S g_{\mathrm{Na}}\right){ }^{*} p<0.05$.

\section{$g_{\mathrm{Na}}$ degrades the precision of coincidence detection}

BCs receive synapses from multiple ANFs and can refine temporal information through coincident activity of these ANFs within a short time window (Burkitt and Clark, 1999; Xu-Friedman and Regehr, 2005a, b; Wang and Manis, 2008; Cao and Oertel, 2010; Chanda and Xu-Friedman, 2010a). In MSO neurons, Na channels can influence EPSPs (Scott et al., 2010), and thereby might affect coincidence detection. We tested this in BCs by examining the effects of $0.5 \mu \mathrm{M}$ TTX on subthreshold EPSPs applied in dynamic clamp. TTX caused EPSPs to get smaller and faster (Fig. $7 A)$, with average amplitudes decreasing by $10.4 \pm 2.4 \%(N=5$, $p<0.01)$ and half-widths decreasing by $36.2 \pm 8.5 \%(p<0.01)$ (Fig. 7C). This indicates that endogenous Na channels play a role in amplifying and slowing EPSPs. However, we were unable to distinguish whether these effects resulted from endogenous somatic or AIS Na channel activation.

To address whether somatic $g_{\mathrm{Na}}$ could amplify EPSPs, we examined the amplitude and time course of subthreshold EPSPs applied in dynamic clamp in the added presence of $1 \mu \mathrm{S} g_{\mathrm{Na}}$. We found that this caused EPSPs to get bigger and slower (Fig. $7 B$ ), with average amplitudes increasing by $11.5 \pm 0.5 \%(N=7, p<$ $0.001)$ and half-width increasing by $33.8 \pm 1.5 \%(p<0.001)$ (Fig. 7C). This raises the possibility that somatic $g_{\mathrm{Na}}$ could cause
EPSPs to summate over longer intervals, reducing the precision of coincidence detection.

To test this possibility, we applied two subthreshold synaptic inputs using dynamic clamp in trains at varying time offsets and quantified AP probability. An example experiment is shown in Figure 7D. The BC fired many APs over the course of the train when the two inputs were simultaneous, but the AP probability decreased as the offset increased $>0.5 \mathrm{~ms}$, reflecting a precise window of coincidence detection.

However, when $g_{\mathrm{Na}}$ was added, we observed two effects. First, the AP probability for simultaneous inputs decreased (Fig. 7E), likely for the reasons explored in Figures 5 and 6 . To focus on other effects, we normalized AP probability at $0 \mathrm{~ms}$ offset to 1 for all $g_{\mathrm{Na}}$ levels. More strikingly, the AP probability was elevated for offset inputs, even when the offset was as large as 5 ms (Fig. $7 E)$. In control $\left(0 \mu \mathrm{S} g_{\mathrm{Na}}\right), \mathrm{AP}$ probability dropped $>50 \%$ for $1 \mathrm{~ms}$ offset. With $g_{\mathrm{Na}} \geq 0.5 \mu \mathrm{S}$, AP probability decreased by only $20 \%$ for $1 \mathrm{~ms}$ offset (Fig. $7 F$ ).

We found similar results in 7 experiments. AP probability increased significantly with $g_{\mathrm{Na}} \geq 0.5 \mu \mathrm{S}$, particularly for offsets $\geq 1 \mathrm{~ms}(N=7, p<0.05$; Fig. $7 G)$. The greatest increases in AP probability were seen at long time intervals (Fig. $7 G)$. We quantified the width of the coincidence window by fitting the AP probability data with the function $P=1 /\left[1+\left(t_{1 / 2} / \Delta t\right)^{1 / k}\right]$, where $t_{1 / 2}$ is the offset at which $P$ drops to $50 \%$. The window was significantly wider for $g_{\mathrm{Na}} \geq 0.5$ $\mu \mathrm{S}(0.74 \pm 0.07 \mathrm{~ms}$ for $0 \mu \mathrm{S}, 1.78 \pm 0.31 \mathrm{~ms}$ for $0.5 \mu \mathrm{S}$, and $2.77 \pm 0.29 \mathrm{~ms}$ for $1 \mu \mathrm{S}, N=5, p<0.018$; Fig. $7 \mathrm{H}$ ), indicating that coincidence detection is less precise with somatic $g_{\mathrm{Na}}$. Thus, EPSPs appeared to activate a small, but significant, endogenous $\mathrm{Na}$ current, which increased and prolonged depolarization. With additional amplification by somatic $g_{\mathrm{Na}}$, EPSPs were more likely to summate and cross threshold, which can decrease precision of coincidence detection.

\section{Discussion}

Here we show that a number of time-coding auditory neurons have APs dominated by activity in the AIS, with a minimal somatic AP. In BCs, this lack of somatic AP appears to result from low $\mathrm{Na}$ channel density and hyperpolarized inactivation voltage sensitivity, similar to what has been described in MSO neurons (Scott et al., 2010). Using dynamic clamp, we showed that minimal $g_{\mathrm{Na}}$ in the soma enhances response to repetitive synaptic activation, most likely by limiting activation of $\mathrm{K}_{\mathrm{V}} 3$ channels. In addition, low somatic $g_{\mathrm{Na}}$ enhances the precision of coincidence detection, probably by minimizing amplification and prolongation of EPSPs by $\mathrm{Na}$ channel activation. Thus, low somatic $g_{\mathrm{Na}}$ appears to be an adaptation for enhancing spiking fidelity and 
precision. This is likely a common principle for additional time-coding neurons in the auditory pathway.

\section{Inactivation}

Our nucleated-patch measurements of somatic Na channels in BCs show activation characteristics highly similar to SCs, but with inactivation sensitivity shifted to more negative potentials. Therefore, at resting membrane potential, there is very little Na current available. This likely explains the lack of somatic AP in BCs.

This raises the question, mechanistically, why BC Na channels have negatively shifted inactivation sensitivity. One possible explanation is that SCs and BCs express different $\mathrm{Na}$ channel $\alpha$ subunits. The most common $\alpha$ subunits in the CNS are $\mathrm{Na}_{\mathrm{V}} 1.1,1.2,1.3$, and 1.6 (Smith and Goldin, 1998; Yu and Catterall, 2003). In expression systems, $\mathrm{Na}_{\mathrm{V}} 1.6$ appears to have the most hyperpolarized inactivation sensitivity, ranging from $V_{1 / 2}=-48$ to $-69 \mathrm{mV}$ in different studies (Isom et al., 1992; Xie et al., 2001; Burbidge et al., 2002; Chen et al., 2008; He and Soderlund, 2014). $\beta$ subunits could also contribute to inactivation voltage sensitivity, depending on the specific $\alpha$ and $\beta$ subunit (Smith and Goldin, 1998; Meadows et al., 2002; Zhao et al., 2011; Calhoun and Isom, 2014). Little is known about which $\alpha$ or $\beta$ subunits are expressed by BCs or SCs.

A second important question is, functionally, why BCs retain $\mathrm{Na}$ channels if they are largely inactivated at rest. In MSO neurons, which also have $\mathrm{Na}$ channels with relatively hyperpolarized inactivation sensitivity, $g_{\mathrm{Na}}$ amplified EPSPs arriving at the dendrites and preserved a linear response (Scott et al., 2010). In our dynamic clamp experiments in BCs, such amplification also had the consequence of driving a cell over threshold even when synaptic inputs were poorly coincident. If that also happened in MSO neurons, it would seem to interfere with their function in sound localization, which likely depends on precise coincidence detection (Goldberg and Brown, 1969; Yin and Chan, 1990; Joris et al., 1998). It is possible that $g_{\mathrm{Na}}$ has less effect on EPSP kinetics in MSO neurons, perhaps because of the anatomical arrangement of synaptic inputs onto distal dendritic branches, whereas in BCs synapses are axosomatic.

\section{Dynamic clamp of $\mathrm{g}_{\mathrm{Na}}$}

Dynamic clamp was very useful in studying the effects of somatic $g_{\mathrm{Na}}$ in BCs. The effects of somatic $g_{\mathrm{Na}}$ on coincidence detection have primarily been studied using pure computer models (Kuba et al., 2006; Ashida et al., 2007). By using dynamic clamp, we could study the effects of $g_{\mathrm{Na}}$ without making assumptions about the characteristics of BCs synapses, AIS Na channels, or K conductances. This could be an issue because the specific properties of AIS Na channels are not well understood and are critical for AP
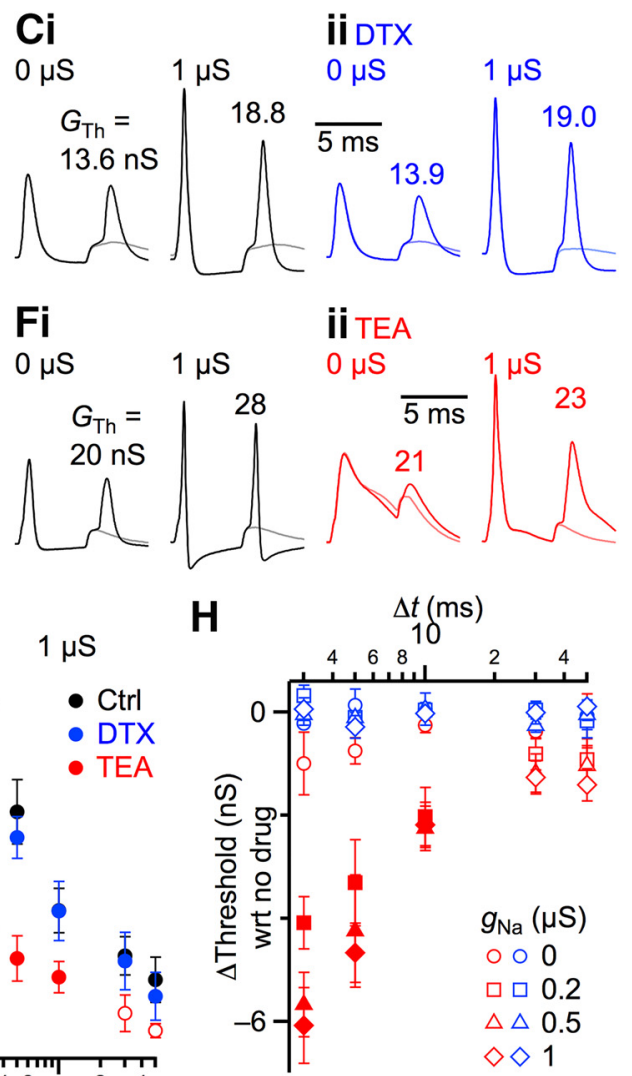

Figure 6. Recruitment of $\mathrm{K}$ channels by somatic $g_{\mathrm{Na}} \cdot A, D$, Representative responses to current injection (600 pA) before (black) $\left(0 \mu S g_{\mathrm{Na}}\right.$ ) before (black, 9 experiments) and after DTX (blue, 4 experiments), or TEA (red, 5 experiments). Threshold increases most ing levels of $g_{\mathrm{Na}}$. Solid symbols represent significant increases in the different conditions at the $p<$ ontrol (no blocker). DTX had no effect on threshold, but adding TEA eliminated increases in threshold. Solid symbols represent significant differences compared with control (no antagonist) in the different conditions at the $p<0.05$ level.

initiation (Colbert and Pan, 2002). Dynamic clamp experiments leave the endogenous AIS intact, which preserves the characteristics of AP initiation as much as possible.

Furthermore, dynamic clamp has advantages over transgenic approaches for increasing $\mathrm{Na}$ channel density because dynamic clamp allows the conductance amplitude to be adjusted over a wide range within a single experiment, so that more conditions can be tested. In addition, acute expression of the $\mathrm{Na}$ conductance by dynamic clamp makes it less likely for other conductances to be upregulated or downregulated, such as in response to changes in activity.

\section{Potassium channels and $g_{\mathrm{Na}}$}

Our study may help illuminate why somatic $g_{\mathrm{Na}}$ levels are low in time-coding neurons. A large somatic $g_{\mathrm{Na}}$ appears to recruit $\mathrm{K}$ channels following APs. Considerable evidence indicates that $\mathrm{K}$ channels contribute to precise spiking in BCs (Manis and Marx, 1991; Brew and Forsythe, 1995; Rothman and Manis, 2003b). $\mathrm{K}_{\mathrm{V}} 1$ channels suppress repetitive APs and accelerate the mem- 

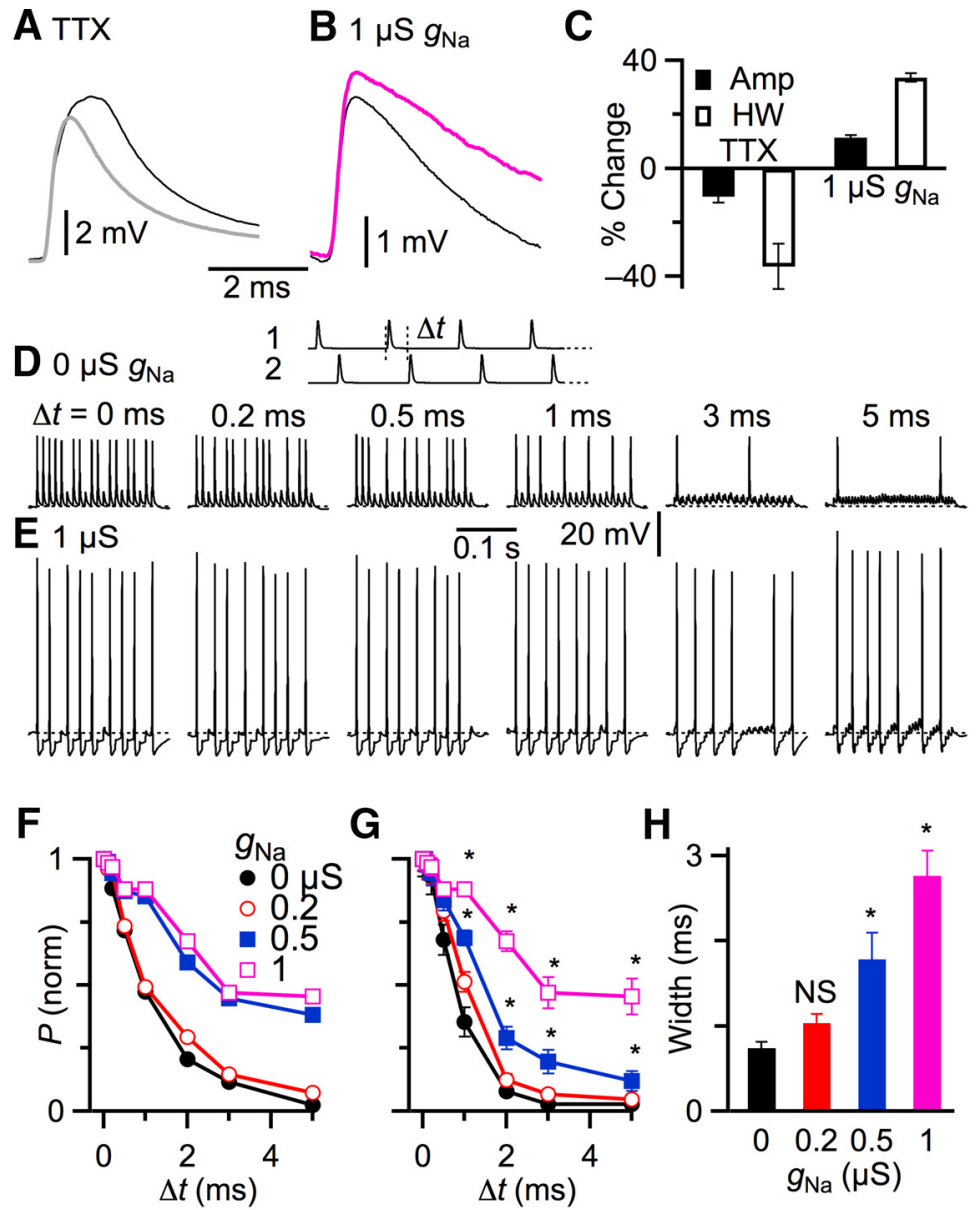

Figure 7. The precision of coincidence detection in BCs is degraded by somatic $g_{\mathrm{Na}} \cdot \boldsymbol{A}$, Effects of blocking endogenous $g_{\mathrm{Na}}$ on subthreshold EPSPs. Traces are averaged EPSPs resulting from a synaptic conductance applied in dynamic clamp, before (black) and after (gray) application of TTX. $\boldsymbol{B}$, Effects of added somatic $g_{\mathrm{Na}}$ on subthreshold EPSPs. Traces are averaged EPSPs resulting from a synaptic conductance without (black) and with (purple) $1 \mu S g_{\mathrm{Na}}$ applied in dynamic clamp. C, Average percentage change in EPSP amplitude and half-width resulting from TTX application or addition of $1 \mu S g_{\mathrm{Na}}$. All results are significantly different from $0(p<$ $0.01) . \boldsymbol{D}, \boldsymbol{E}$, Assessing the window of coincidence detection. Schematic at top represents the stimulation paradigm, which was two $100 \mathrm{~Hz}$ trains of subthreshold synaptic conductances with a time offset $(\Delta t)$. Traces show representative responses to this stimulation paradigm for several $\Delta t,(\boldsymbol{D})$ without and $(\boldsymbol{E})$ with $1 \mu S g_{\mathrm{Na}}$ applied by dynamic clamp. $\boldsymbol{F}$, AP probability for the representative experiment in $\boldsymbol{D}$ and $\boldsymbol{E}$. AP probability is normalized to 1 at zero offset between the trains. $\boldsymbol{G}$, Summary of 7 similar experiments showing average AP probability as a function of offset with different amounts of $g_{\mathrm{Na}} . \boldsymbol{H}$, Average width of the coincidence window across 7 experiments for different amounts of $g_{\mathrm{Na}}{ }^{*} p<0.018$, significant differences with respect to control $\left(0 \mu S g_{\mathrm{Na}}\right)$.

brane time constant so that BCs respond rapidly and with only a single AP to synaptic activity (Manis and Marx, 1991; Rothman and Manis, 2003a; Cao et al., 2007; Cao and Oertel, 2010). They also help suppress APs driven by asynchronous neurotransmitter release (Yang and Xu-Friedman, 2010).

The $\mathrm{K}_{\mathrm{V}} 3$ channels contribute to rapid AP repolarization and the AHP, which speeds recovery of $\mathrm{Na}$ channels from inactivation (Manis and Marx, 1991; Wang et al., 1998), so a $\mathrm{BC}$ can be ready as rapidly as possible for the next EPSP. Indeed, for time-coding auditory neurons in the MNTB, $\mathrm{K}_{\mathrm{V}} 3$ channels appear to be upregulated in response to high levels of activity, which supports rapid spiking (Song et al., 2005). However, our results suggest that, if $\mathrm{K}_{\mathrm{V}} 3$ activation is too strong, it may suppress synaptically evoked APs (Fig. 6). Neurons with low somatic $g_{\mathrm{Na}}$ may thereby moderate activation of $\mathrm{K}_{\mathrm{V}} 3$, which could optimize responses to rapid synaptic input. Our experiments reveal that the balance of potassium channel activation must be carefully regulated.
Time-coding neurons show unusually high expression of $\mathrm{K}$ conductances, which has led to intense experimental and modeling investigation for many years: in BCs (Manis and Marx, 1991; Rothman and Manis, 2003a); in MSO (Svirskis et al., 2003; Scott et al., 2010; Khurana et al., 2011); in MNTB (Brew and Forsythe, 1995; Wang et al., 1998; Klug and Trussell, 2006); in octopus cells (Golding et al., 1999; Bal and Oertel, 2001). Such results as well as ours underscore that the interactions can be complex and unexpected, particularly in the context of AP initiation.

\section{Somatic AP and precise timing}

The group of time-coding neurons in the auditory pathway we examined are unusual in that they display exceptional fidelity and precision while also experiencing extremely high levels of activity, of up to $500 \mathrm{~Hz}$ (Johnson, 1980; Joris et al., 1994; Taberner and Liberman, 2005; Lorteije et al., 2009). These neurons also had reduced AP amplitudes, and phaseplane plots indicated that this likely results from activity only in the AIS and not the soma. MSO neurons in gerbils also have reduced APs, and their somatic $\mathrm{Na}$ channels also have hyperpolarized voltage sensitivity (Scott et al., 2010). These adaptations are likely shared by octopus cells, which have very reduced AP amplitudes.

MNTB neurons differ somewhat from the other time-coding neurons we have focused on. The MNTB AP reaches a higher peak than BCs, MSO neurons, and octopus cells. On the other hand, the AP size is lower than conventional neurons and only a single phase is discernible, indicating that the soma has unusually low $\mathrm{Na}$ channel activation. Na currents have been examined in MNTB neurons in a few studies (e.g., Leão et al., 2006; Johnston et al., 2008), and they have not shown unusual characteristics, although the experimental conditions differ significantly from the ones used here, in terms of temperature, maturation, and whether the recordings include both soma and AIS. It may be that the AIS is electrotonically close to the soma, which would yield midsized AP amplitude with a single phase. It will be interesting to investigate the mechanism for these reduced APs in MNTB further and how they may influence spiking.

Indeed, in neurons of the avian nucleus magnocellularis, which have similar function to BCs in the mammalian AVCN, AP amplitude varies tonotopically, with high- and middle-frequency neurons showing the smallest AP amplitude, and low-frequency neurons having relatively tall APs (Kuba and Ohmori, 2009). This seems to correlate with the length and intensity of AIS immunostaining for Na channels. Computer simulations suggested that a high density in the AIS could enhance responsiveness, particularly to small synaptic inputs (Kuba and Ohmori, 2009). This effect seems similar to the widening we observed for the window 
of coincidence detection upon adding somatic $g_{\mathrm{Na}}$ to real neurons using dynamic clamp (Fig. 7). Thus, amplification of EPSPs can have both positive and negative consequences.

In non-time-coding neurons, the adaptive pressures may be quite different. First, activity levels may be lower and precision less stringent, so the negative consequences of somatic $\mathrm{Na}$ channels may be low. Furthermore, somatic Na channels may support additional functions. Synapses on distal dendrites may use information about spiking activity to dictate long-term plasticity. Passive back-propagation from the AIS alone may be inadequate without amplification by $\mathrm{Na}$ channels in the soma. This seems most important in neurons that express long-term plasticity in extremely large dendrites, such as in cortex or hippocampus (Magee and Johnston, 1997; Markram et al., 1997).

Remarkably, few forms of long-term plasticity have been described in the time-coding auditory neurons, so it is possible that retrograde signaling is less important (Taschenberger and von Gersdorff, 2000; Futai et al., 2001; Joshi et al., 2007). In MSO neurons, a role has been proposed for $\mathrm{Na}$ channels in anterograde dendritic signaling (Scott et al., 2010). The dendrites of BCs appear to largely receive inhibitory inputs (Ostapoff and Morest, 1991), so it may be that somatic Na channels have little benefit. Thus, it appears that there are primarily significant costs to expressing Na channels in the somata of BCs, so lacking them seems more adaptively advantageous.

\section{References}

Adam TJ, Schwarz DW, Finlayson PG (1999) Firing properties of chopper and delay neurons in the lateral superior olive of the rat. Exp Brain Res 124:489-502. CrossRef Medline

Ashida G, Abe K, Funabiki K, Konishi M (2007) Passive soma facilitates submillisecond coincidence detection in the owl's auditory system. J Neurophysiol 97:2267-2282. CrossRef Medline

Bal R, Oertel D (2001) Potassium currents in octopus cells of the mammalian cochlear nucleus. J Neurophysiol 86:2299-2311. Medline

Bean BP (2007) The action potential in mammalian central neurons. Nat Rev Neurosci 8:451-465. CrossRef Medline

Brand A, Behrend O, Marquardt T, McAlpine D, Grothe B (2002) Precise inhibition is essential for microsecond interaural time difference coding. Nature 417:543-547. CrossRef Medline

Brew HM, Forsythe ID (1995) Two voltage-dependent $\mathrm{K}^{+}$conductances with complementary functions in postsynaptic integration at a central auditory synapse. J Neurosci 15:8011-8022. Medline

Burbidge SA, Dale TJ, Powell AJ, Whitaker WR, Xie XM, Romanos MA, Clare JJ (2002) Molecular cloning, distribution and functional analysis of the $\mathrm{NA}(\mathrm{V}) 1.6$ : voltage-gated sodium channel from human brain. Brain Res Mol Brain Res 103:80-90. CrossRef Medline

Burkitt AN, Clark GM (1999) Analysis of integrate-and-fire neurons: synchronization of synaptic input and spike output. Neural Comput 11:871901. CrossRef Medline

Calhoun JD, Isom LL (2014) The role of non-pore-forming beta subunits in physiology and pathophysiology of voltage-gated sodium channels. Handb Exp Pharmacol 221:51-89. CrossRef Medline

Cao XJ, Oertel D (2010) Auditory nerve fibers excite targets through synapses that vary in convergence, strength, and short-term plasticity. J Neurophysiol 104:2308-2320. CrossRef Medline

Cao XJ, Shatadal S, Oertel D (2007) Voltage-sensitive conductances of bushy cells of the mammalian ventral cochlear nucleus. J Neurophysiol 97:3961-3975. CrossRef Medline

Chanda S, Xu-Friedman MA (2010a) Neuromodulation by GABA converts a relay into a coincidence detector. J Neurophysiol 104:2063-2074. CrossRef Medline

Chanda S, Xu-Friedman MA (2010b) A low-affinity antagonist reveals saturation and desensitization in mature synapses in the auditory brain stem. J Neurophysiol 103:1915-1926. CrossRef Medline

Chen Y, Yu FH, Sharp EM, Beacham D, Scheuer T, Catterall WA (2008) Functional properties and differential neuromodulation of $\mathrm{Na}(\mathrm{v}) 1.6$ channels. Mol Cell Neurosci 38:607-615. CrossRef Medline

Colbert CM, Pan E (2002) Ion channel properties underlying axonal action potential initiation in pyramidal neurons. Nat Neurosci 5:533-538. CrossRef Medline

Edwards C, Ottoson D (1958) The site of impulse initiation in a nerve cell of a crustacean stretch receptor. J Physiol 143:138-148. CrossRef Medline

Frisina RD, Smith RL, Chamberlain SC (1985) Differential encoding of rapid changes in sound amplitude by second-order auditory neurons. Exp Brain Res 60:417-422. Medline

Futai K, Okada M, Matsuyama K, Takahashi T (2001) High-fidelity transmission acquired via a developmental decrease in NMDA receptor expression at an auditory synapse. J Neurosci 21:3342-3349. Medline

Gentet LJ, Stuart GJ, Clements JD (2000) Direct measurement of specific membrane capacitance in neurons. Biophys J 79:314-320. CrossRef Medline

Gittelman JX, Tempel BL (2006) Kv1.1-containing channels are critical for temporal precision during spike initiation. J Neurophysiol 96:1203-1214. CrossRef Medline

Goldberg JM, Brown PB (1969) Response of binaural neurons of dog superior olivary complex to dichotic tonal stimuli: some physiological mechanisms of sound localization. J Neurophysiol 32:613-636. Medline

Golding NL, Robertson D, Oertel D (1995) Recordings from slices indicate that octopus cells of the cochlear nucleus detect coincident firing of auditory nerve fibers with temporal precision. J Neurosci 15:3138-3153. Medline

Golding NL, Ferragamo MJ, Oertel D (1999) Role of intrinsic conductances underlying responses to transients in octopus cells of the cochlear nucleus. J Neurosci 19:2897-2905. Medline

Grigg JJ, Brew HM, Tempel BL (2000) Differential expression of voltagegated potassium channel genes in auditory nuclei of the mouse brainstem. Hear Res 140:77-90. CrossRef Medline

Grothe B (2003) New roles for synaptic inhibition in sound localization. Nat Rev Neurosci 4:540-550. CrossRef Medline

He B, Soderlund DM (2014) Functional expression of Rat Nav1.6 voltagegated sodium channels in HEK293 cells: modulation by the auxiliary betal subunit. PLoS One 9:e85188. CrossRef Medline

Isom LL, De Jongh KS, Patton DE, Reber BF, Offord J, Charbonneau H, Walsh K, Goldin AL, Catterall WA (1992) Primary structure and functional expression of the beta 1 subunit of the rat brain sodium channel. Science 256:839-842. CrossRef Medline

Johnson DH (1980) The relationship between spike rate and synchrony in responses of auditory-nerve fibers to single tones. J Acoust Soc Am 68: 1115-1122. CrossRef Medline

Johnston J, Griffin SJ, Baker C, Skrzypiec A, Chernova T, Forsythe ID (2008) Initial segment Kv2.2 channels mediate a slow delayed rectifier and maintain high frequency action potential firing in medial nucleus of the trapezoid body neurons. J Physiol 586:3493-3509. CrossRef Medline

Joris PX, Carney LH, Smith PH, Yin TC (1994) Enhancement of neural synchronization in the anteroventral cochlear nucleus: I. Responses to tones at the characteristic frequency. J Neurophysiol 71:1022-1036. Medline

Joris PX, Smith PH, Yin TC (1998) Coincidence detection in the auditory system: 50 years after Jeffress. Neuron 21:1235-1238. CrossRef Medline

Joshi I, Yang YM, Wang LY (2007) Coincident activation of metabotropic glutamate receptors and NMDA receptors (NMDARs) downregulates perisynaptic/extrasynaptic NMDARs and enhances high-fidelity neurotransmission at the developing calyx of Held synapse. J Neurosci 27: 9989-9999. CrossRef Medline

Khurana S, Remme MW, Rinzel J, Golding NL (2011) Dynamic interaction of Ih and IK-LVA during trains of synaptic potentials in principal neurons of the medial superior olive. J Neurosci 31:8936-8947. CrossRef Medline

Kim DO, Sirianni JG, Chang SO (1990) Responses of DCN-PVCN neurons and auditory nerve fibers in unanesthetized decerebrate cats to AM and pure tones: analysis with autocorrelation/power-spectrum. Hear Res 45: 95-113. CrossRef Medline

Klug A, Trussell LO (2006) Activation and deactivation of voltagedependent $\mathrm{K}^{+}$channels during synaptically driven action potentials in the MNTB. J Neurophysiol 96:1547-1555. CrossRef Medline

Kuba H, Ohmori H (2009) Roles of axonal sodium channels in precise auditory time coding at nucleus magnocellularis of the chick. J Physiol 587: 87-100. CrossRef Medline

Kuba H, Ishii TM, Ohmori H (2006) Axonal site of spike initiation enhances auditory coincidence detection. Nature 444:1069-1072. CrossRef Medline 
Kuwabara N, DiCaprio RA, Zook JM (1991) Afferents to the medial nucleus of the trapezoid body and their collateral projections. J Comp Neurol 314:684-706. CrossRef Medline

Leão RN, Naves MM, Leão KE, Walmsley B (2006) Altered sodium currents in auditory neurons of congenitally deaf mice. Eur J Neurosci 24:11371146. CrossRef Medline

Lehnert S, Ford MC, Alexandrova O, Hellmundt F, Felmy F, Grothe B, Leibold C (2014) Action potential generation in an anatomically constrained model of medial superior olive axons. J Neurosci 34:5370-5384. CrossRef Medline

Lorteije JA, Rusu SI, Kushmerick C, Borst JG (2009) Reliability and precision of the mouse calyx of Held synapse. J Neurosci 29:13770-13784. CrossRef Medline

Magee JC, Johnston D (1997) A synaptically controlled, associative signal for Hebbian plasticity in hippocampal neurons. Science 275:209-213. CrossRef Medline

Manis PB, Marx SO (1991) Outward currents in isolated ventral cochlear nucleus neurons. J Neurosci 11:2865-2880. Medline

Markram H, Lübke J, Frotscher M, Sakmann B (1997) Regulation of synaptic efficacy by coincidence of postsynaptic APs and EPSPs. Science 275: 213-215. CrossRef Medline

Meadows LS, Chen YH, Powell AJ, Clare JJ, Ragsdale DS (2002) Functional modulation of human brain Nav1.3 sodium channels, expressed in mammalian cells, by auxiliary beta 1, beta 2 and beta 3 subunits. Neuroscience 114:745-753. CrossRef Medline

Ngodup T, Goetz JA, McGuire BC, Sun W, Lauer AM, Xu-Friedman MA (2015) Activity-dependent, homeostatic regulation of neurotransmitter release from auditory nerve fibers. Proc Natl Acad Sci U S A 112:64796484. CrossRef Medline

Oertel D (1983) Synaptic responses and electrical properties of cells in brain slices of the mouse anteroventral cochlear nucleus. J Neurosci 3:20432053. Medline

Oertel D, Wu SH (1989) Morphology and physiology of cells in slice preparations of the dorsal cochlear nucleus of mice. J Comp Neurol 283:228247. CrossRef Medline

Oertel D, Bal R, Gardner SM, Smith PH, Joris PX (2000) Detection of synchrony in the activity of auditory nerve fibers by octopus cells of the mammalian cochlear nucleus. Proc Natl Acad Sci U S A 97:11773-11779. CrossRef Medline

Ostapoff EM, Morest DK (1991) Synaptic organization of globular bushy cells in the ventral cochlear nucleus of the cat: a quantitative study. J Comp Neurol 314:598-613. CrossRef Medline

Roberts MT, Seeman SC, Golding NL (2014) The relative contributions of MNTB and LNTB neurons to inhibition in the medial superior olive assessed through single and paired recordings. Front Neural Circuits 8:49. CrossRef Medline

Rothman JS, Manis PB (2003a) The roles potassium currents play in regulating the electrical activity of ventral cochlear nucleus neurons. J Neurophysiol 89:3097-3113. CrossRef Medline

Rothman JS, Manis PB (2003b) Differential expression of three distinct potassium currents in the ventral cochlear nucleus. J Neurophysiol 89:30703082. CrossRef Medline

Schmidt-Hieber C, Bischofberger J (2010) Fast sodium channel gating supports localized and efficient axonal action potential initiation. J Neurosci 30:10233-10242. CrossRef Medline

Scott LL, Mathews PJ, Golding NL (2005) Posthearing developmental refinement of temporal processing in principal neurons of the medial superior olive. J Neurosci 25:7887-7895. CrossRef Medline

Scott LL, Mathews PJ, Golding NL (2010) Perisomatic voltage-gated sodium channels actively maintain linear synaptic integration in principal neurons of the medial superior olive. J Neurosci 30:2039-2050. CrossRef Medline

Shore SE (2005) Multisensory integration in the dorsal cochlear nucleus: unit responses to acoustic and trigeminal ganglion stimulation. Eur J Neurosci 21:3334-3348. CrossRef Medline

Smith PH, Joris PX, Carney LH, Yin TC (1991) Projections of physiologi- cally characterized globular bushy cell axons from the cochlear nucleus of the cat. J Comp Neurol 304:387-407. CrossRef Medline

Smith RD, Goldin AL (1998) Functional analysis of the rat I sodium channel in Xenopus oocytes. J Neurosci 18:811-820. Medline

Song P, Yang Y, Barnes-Davies M, Bhattacharjee A, Hamann M, Forsythe ID, Oliver DL, Kaczmarek LK (2005) Acoustic environment determines phosphorylation state of the Kv3.1 potassium channel in auditory neurons. Nat Neurosci 8:1335-1342. CrossRef Medline

Spirou GA, Brownell WE, Zidanic M (1990) Recordings from cat trapezoid body and hrp labeling of globular bushy cell axons. J Neurophysiol 63: 1169-1190. Medline

Sterenborg JC, Pilati N, Sheridan CJ, Uchitel OD, Forsythe ID, Barnes-Davies M (2010) Lateral olivocochlear (LOC) neurons of the mouse LSO receive excitatory and inhibitory synaptic inputs with slower kinetics than LSO principal neurons. Hear Res 270:119-126. CrossRef Medline

Svirskis G, Dodla R, Rinzel J (2003) Subthreshold outward currents enhance temporal integration in auditory neurons. Biol Cybern 89:333-340. CrossRef Medline

Taberner AM, Liberman MC (2005) Response properties of single auditory nerve fibers in the mouse. J Neurophysiol 93:557-569. CrossRef Medline

Taschenberger H, von Gersdorff H (2000) Fine-tuning an auditory synapse for speed and fidelity: developmental changes in presynaptic waveform, EPSC kinetics, and synaptic plasticity. J Neurosci 20:9162-9173. Medline

Vetter DE, Mugnaini E (1992) Distribution and dendritic features of three groups of rat olivocochlear neurons: a study with two retrograde cholera toxin tracers. Anat Embryol (Berl) 185:1-16. CrossRef Medline

von Gersdorff H, Borst JG (2002) Short-term plasticity at the calyx of Held. Nat Rev Neurosci 3:53-64. CrossRef Medline

Wang H, Kunkel DD, Schwartzkroin PA, Tempel BL (1994) Localization of Kv1.1 and Kv1.2, two K channel proteins, to synaptic terminals, somata, and dendrites in the mouse brain. J Neurosci 14:4588-4599. Medline

Wang LY, Gan L, Forsythe ID, Kaczmarek LK (1998) Contribution of the Kv3.1 potassium channel to high-frequency firing in mouse auditory neurones. J Physiol 509:183-194. CrossRef Medline

Wang Y, Manis PB (2008) Short-term synaptic depression and recovery at the mature mammalian endbulb of Held synapse in mice. J Neurophysiol 100:1255-1264. CrossRef Medline

Wu SH, Oertel D (1984) Intracellular injection with horseradish peroxidase of physiologically characterized stellate and bushy cells in slices of mouse anteroventral cochlear nucleus. J Neurosci 4:1577-1588. Medline

Xie X, Dale TJ, John VH, Cater HL, Peakman TC, Clare JJ (2001) Electrophysiological and pharmacological properties of the human brain type IIA $\mathrm{Na}^{+}$channel expressed in a stable mammalian cell line. Pflugers Arch 441:425-433. CrossRef Medline

Xu-Friedman MA, Regehr WG (2005a) Dynamic-clamp analysis of the effects of convergence on spike timing: I. Many synaptic inputs. J Neurophysiol 94:2512-2525. CrossRef Medline

Xu-Friedman MA, Regehr WG (2005b) Dynamic-clamp analysis of the effects of convergence on spike timing: II. Few synaptic inputs. J Neurophysiol 94:2526-2534. CrossRef Medline

Yang H, Xu-Friedman MA (2010) Developmental mechanisms for suppressing the effects of delayed release at the endbulb of Held. J Neurosci 30:11466-11475. CrossRef Medline

Yang Y, Xu-Friedman MA (2015) Different pools of glutamate receptors mediate sensitivity to ambient glutamate in the cochlear nucleus. J Neurophysiol 113:3634-3645. CrossRef Medline

Yang Y, Adowski T, Ramamurthy B, Neef A, Xu-Friedman MA (2015) High-speed dynamic-clamp interface. J Neurophysiol 113:2713-2720. CrossRef Medline

Yin TC, Chan JC (1990) Interaural time sensitivity in medial superior olive of cat. J Neurophysiol 64:465-488. Medline

Yu FH, Catterall WA (2003) Overview of the voltage-gated sodium channel family. Genome Biol 4:207. CrossRef Medline

Zhao J, O'Leary ME, Chahine M (2011) Regulation of Nav1.6 and Nav1.8 peripheral nerve $\mathrm{Na}^{+}$channels by auxiliary beta-subunits. J Neurophysiol 106:608-619. CrossRef Medline 